\title{
A near-fatal infection with oseltamivir-resistant seasonal influenza $A$ in a previously healthy child: Case report
}

\author{
Jesse Papenburg MD ${ }^{1,2}$, Christos Karatzios $\mathrm{MD}^{1}$, Yan $\mathrm{Li} \mathrm{PhD}^{3}$, Nathalie Bastien $\mathrm{PhD}^{3}$, \\ Makeda Semret MD MSc${ }^{2}$, Dorothy Moore MD PhD ${ }^{1}$
}

\begin{abstract}
J Papenburg, C Karatzios, Y Li, N Bastien, M Semret, D Moore. A near-fatal infection with oseltamivir-resistant seasonal influenza $\mathrm{A}$ in a previously healthy child: Case report. Can J Infect Dis Med Microbiol 2009;20(4):e173-e176.

A case of near-fatal oseltamivir-resistant seasonal influenza A infection in a previously healthy four-year-old boy is reported. This case highlights three important points for physicians: oseltamivir-resistant influenza A (H1N1) has recently emerged in North America; contrary to previously held beliefs, such strains are capable of causing severe disease in healthy children; and given this change in epidemiology, clinicians caring for children with severe seasonal influenza A infection should consider empiric dual therapy with oseltamivir and amantadine.
\end{abstract}

Key Words: Amantadine; Child; Drug Resistance; Human; Influenza; Oseltamivir; Viral

Tnfluenza is a major cause of respiratory illness leading to hos1 pitalization in previously healthy children, especially among those younger than two years of age $(1,2)$. A Canadian surveillance study of pediatric hospitalizations for influenza in 2003 2004 noted that $12 \%$ required intensive care unit (ICU) admission and $6 \%$ mechanical ventilation (3). While immunization is the cornerstone of current influenza prevention strategies (4), antiviral therapy remains the only specific treatment for this disease $(5,6)$.

\section{CASE PRESENTATION}

In February 2008, a four-year-old boy was transferred from a community hospital to the Montreal Children's Hospital (Montreal, Quebec) because of respiratory distress. He had no significant antecedent medical history, attended daycare, and had never traveled outside of Canada. His vaccination schedule was complete, except that he had never received influenza immunization.

The patient's illness began $12 \mathrm{~h}$ before seeking medical attention, when he developed fever and cough. He presented to a community hospital with worsening symptoms. He was given supplemental oxygen for hypoxia, and was treated with oral amoxicillin for a suspected right middle lobe pneumonia (Figure 1A). Over the following $12 \mathrm{~h}$, he developed progressive respiratory distress and was transferred to the Montreal Children's Hospital. Upon arrival, he was febrile $\left(39^{\circ} \mathrm{C}\right.$ rectally), tachypneic (60 breaths/min), tachycardic (156 beats/min), hypoxic

\section{Infection quasi fatale par un virus de la grippe A saisonnière résistant à l'oseltamivir chez un enfant auparavant en bonne santé : Rapport de} cas

On présente ici le cas d'un garçonnet de quatre ans auparavant en bonne santé qui a failli mourir des suites d'une infection par un virus de la grippe A saisonnière résistant à l'oseltamivir. Ce cas rappelle trois points importants pour les médecins : une souche de grippe A (H1N1) résistante à l'oseltamivir a récemment fait son apparition en Amérique du Nord; contrairement à ce que l'on croyait auparavant, de telles souches peuvent causer une maladie grave chez des enfants en bonne santé; et compte tenu de ce changement épidémiologique, les médecins qui soignent des enfants atteints de grippe A saisonnière grave doivent envisager le recours à un double traitement empirique par oseltamivir et amantadine.

\footnotetext{
${ }^{1}$ Infectious Diseases Division, Department of Pediatrics, Montreal Children's Hospital; ${ }^{2}$ Department of Microbiology, McGill University Health Centre, Montreal, Québec; ${ }^{3}$ National Microbiology Laboratory, Canadian Science Center for Human and Animal Health, Winnipeg, Manitoba 

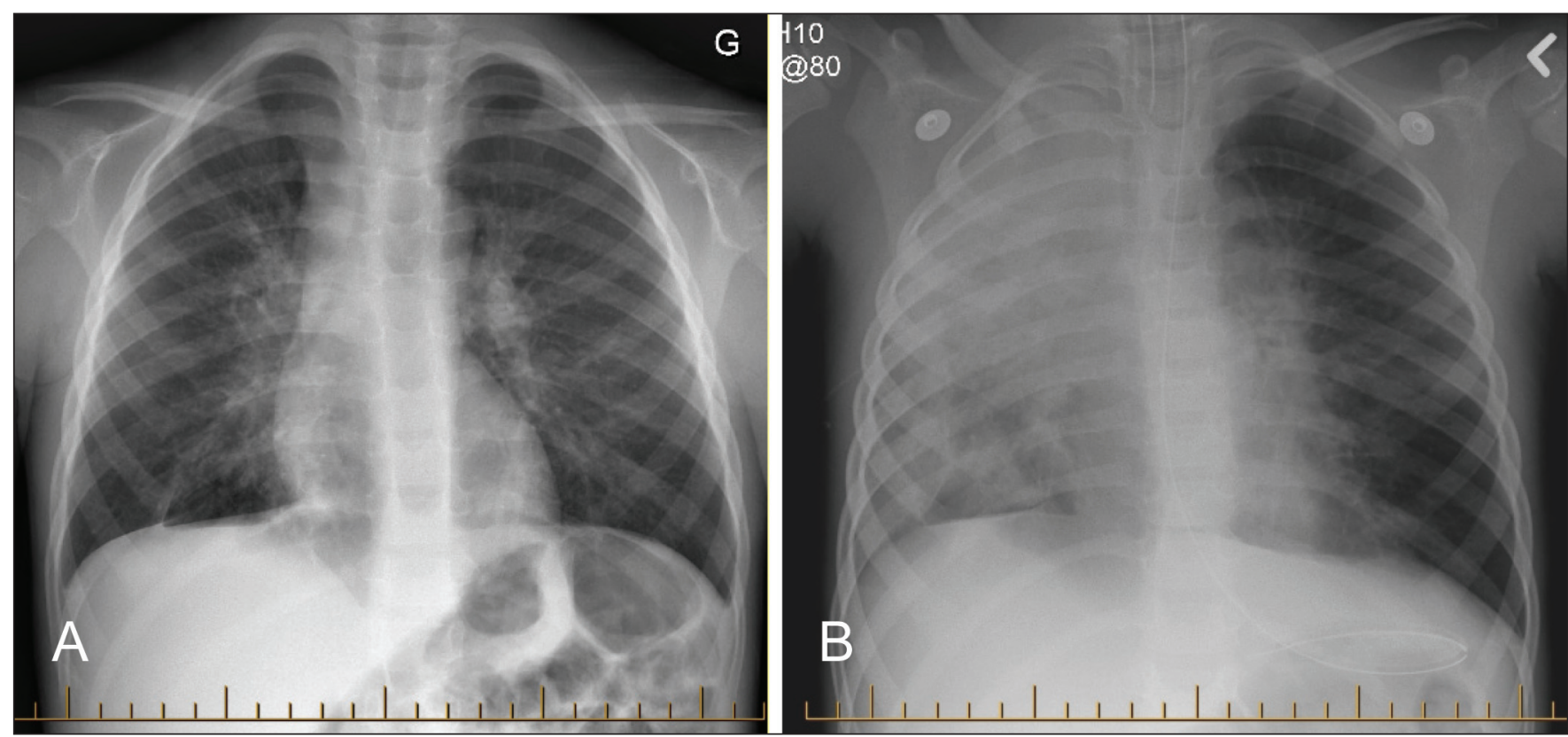

Figure 1) Chest radiographs. A Hospital day 1, at the referring community hospital. B Hospital day 1, after admission to the Montreal Children's Hospital, Montreal, Quebec

\section{TABLE 1}

\section{Virological analysis of nasopharyngeal aspirates}

\begin{tabular}{|c|c|c|c|c|c|}
\hline $\begin{array}{l}\text { Hospital } \\
\text { day }\end{array}$ & DFA & Cell culture & $\begin{array}{c}\text { Multiplex } \\
\text { PCR }\end{array}$ & $\begin{array}{c}\text { Oseltamivir } \\
\text { susceptibility }\end{array}$ & $\begin{array}{l}\text { Amantadine } \\
\text { susceptibility }\end{array}$ \\
\hline 1 & Influenza A & Negative & Not tested & $\mathrm{R}$ & $\mathrm{S}$ \\
\hline 5 & Influenza A & Influenza A & Not tested & $\mathrm{R}$ & $\mathrm{S}$ \\
\hline 7 & Influenza A & Influenza A & Influenza A & $\mathrm{R}$ & $\mathrm{R}$ \\
\hline 13 & Negative & Negative & Influenza A & Not tested & Not tested \\
\hline
\end{tabular}

DFA Direct immunofluorescence assay; PCR Polymerase chain reaction; R Resistant; S Susceptible

serological testing was negative. Immunoglobulin levels and total lymphocyte counts were normal.

Because the child required maximal ventilatory support settings, extracorporeal membrane oxygenation was considered on several occasions, but was never initiated. Because the patient continued to deteriorate on oseltamivir therapy, amantadine (160 mg daily via nasogastric tube) was added on hospital day 5. An NPA obtained just before the initiation of amantadine remained positive for influenza A by DFA and culture.

The child's respiratory status began to improve during the second week of hospitalization and he was extubated 18 days after admission. He received oseltamivir plus amantadine from day 5 to day 11. Despite no microbiological evidence of bacterial coinfection, he was treated with a course of 18 days of cefuroxime and five days of azithromycin.

After discharge, the boy required physiotherapy for critical illness myopathy, but subsequently recovered fully.

Table 1 describes the virological analysis of the patient's NPAs. Influenza A was the only agent identified. The infecting strain was subtyped A/Solomon Islands/03/06 (H1N1) by the National Microbiology Laboratory. On days 1, 5 and 7, DFA was positive for influenza $A$ and negative for a panel of seven other respiratory viruses: influenza B, adenovirus, human metapneumovirus, respiratory syncytial virus and parainfluenza viruses 1, 2 and 3. Influenza A was isolated in cell culture from the samples from days 5 and 7. Incidentally, the NPAs from days 7 and 13 were also tested for 10 respiratory viruses by an in-house multiplex real-time polymerase chain reaction (PCR) assay in the context of a validation study (7). In addition to the eight viruses in the aforementioned DFA panel, the PCR panel included coronaviruses OC43 and 229E. PCR was positive on both occasions for influenza A only.

Samples from days 1, 5 and 7 were later analyzed at the National Microbiology Laboratory for antiviral susceptibilities. All three specimens were positive for the H274Y mutation conferring oseltamivir resistance. Isolates from days 5 and 7 were also tested by the neuraminidase inhibition assay and exhibited phenotypic resistance to oseltamivir (ie, a 50\% inhibitory concentration greater than three standard deviations above the mean for wild-type virus). Samples from days 1 and 5 - taken before amantadine therapy - were negative for amantadine resistance by nucleic acid sequence analysis. Genotypic resistance to amantidine, a S31N mutation in the M2 gene, was detected in the isolate from day 7.

\section{DISCUSSION}

Little is known about the treatment of severe influenza in children, although it has been postulated that these cases would benefit the most from specific antiviral therapy (5). Indeed, improved outcomes, including decreased mortality, have been reported in adults hospitalized $(8,9)$ or admitted to the ICU (10) who received antivirals for influenza.

There are two classes of drugs approved for the treatment of influenza: the adamantanes (M2 ion-channel blockers) and the neuraminidase inhibitors (NI). Both classes are effective in the treatment and prophylaxis of infection in children and adults, especially when administered within the first $48 \mathrm{~h}$ of symptoms $(5,6)$.

Adamantanes are active only against influenza A. Amantadine is the only drug of this class available in Canada and it is licensed for use in children one year of age and older.

Point mutations in the viral M2 gene confer complete crossresistance to all adamantanes (11). Resistance occurs readily 
on treatment, especially in children. Resistant strains are as transmissible and as virulent as wild-type virus (12). Adamantane resistance in circulating influenza A has increased dramatically worldwide (13). Consequently, since January 2006, this class of drugs is not recommended by the Public Health Agency of Canada and the Centers for Disease Control for the treatment and prevention of influenza. During the 2007-2008 season in North America, over 99.5\% of influenza A (H3N2) and up to $11 \%$ of influenza A (H1N1) were resistant to adamantanes $(14,15)$.

Oseltamivir and zanamivir are the two NI currently available. They are active against both influenza A and B (16). Oseltamivir is an oral drug licensed for use in children one year of age and older. Zanamivir is only available for administration by inhalation of a dry powder, and is therefore less suitable for critically ill patients, especially those requiring ventilatory support (17). It is not licensed for use in children younger than seven years of age.

Point mutations in the neuraminidase gene that prevent oseltamivir from binding to its target site cause viral resistance to this agent, but not cross-resistance to zanamivir (18). Before 2007, naturally occurring resistance to NI in influenza was rare, estimated to be only $0.2 \%$ (19). Moreover, compared with the adamantanes, NI are much less prone to selecting for resistant virus. Nevertheless, $1 \%$ to $4 \%$ of adults and up to $18 \%$ of children can excrete oseltamivir-resistant virus when exposed to the drug (20). Resistance to zanamivir remains exceedingly rare (21).

The clinical relevance of oseltamivir resistance was not fully appreciated until very recently. In 2006-2007, resistant strains represented only $0.1 \%$ of influenza isolates in Canada (22). However, during the 2007-2008 season, oseltamivir resistance rates for influenza $\mathrm{A}$ rose dramatically to $17.8 \%$ in Canada (14) and 7.6\% in the United States (15). All resistant isolates were influenza $\mathrm{A}(\mathrm{H} 1 \mathrm{~N} 1)$ and all shared the same $\mathrm{H} 274 \mathrm{Y}$ mutation in the neuraminidase gene when tested by nucleic acid sequencing. No isolates tested resistant to zanamivir. Most recently, 99.7\% of 2008-2009 seasonal influenza A (H1N1) in Canada was resistant to oseltamivir (23) and high rates of resistance have been reported worldwide in all age groups (24).

Our patient's failure to respond to oseltamivir highlights the emergence of naturally circulating seasonal influenza A (H1N1) carrying the $\mathrm{H} 274 \mathrm{Y}$ mutation conferring oseltamivir resistance. This child had not been exposed to a NI before viral testing, and he had not been in contact with anybody on antiviral treatment for influenza.

Based on in vitro and animal data, it has been suggested that H274Y mutants are less biologically fit due to decreased infectivity, replicative ability and pathogenicity $(25,26)$. The authors of one industry-run trial went so far as to state that "virus carrying a H274Y mutation is unlikely to be of clinical consequence in man" (26). The current epidemiology of influenza A (H1N1) in North America clearly attests to the transmissibility of these mutant viruses. Until now, there has been only one report of a fatal infection due to oseltamivir-resistant influenza A (H1N1) carrying the H274Y amino acid substitution (27). However, this 67-year-old patient was profoundly immunocompromised, undergoing cytotoxic chemotherapy for chronic lymphocytic leukemia. His hospitalization was also complicated by bloodstream infections with Candida albicans and Enterococcus faecium. The case that we describe demonstrates that, contrary to previous suggestions, oseltamivir-resistant influenza A is capable of causing severe disease in a previously healthy patient with no apparent immunodeficiency.

It has been previously recommended that combination therapy with a NI and amantadine be considered in seriously ill patients (6), based on reports of additive or synergistic effects in in vitro (28) and animal studies (29), and a small clinical trial (30). We believe that the emergence of antiviral resistance in influenza represents the basis for a new argument in favour of combination therapy in severe influenza A infections. Because influenza subtyping and antiviral resistance testing are not readily available to clinicians, they must treat empirically. Therefore, it appears that we have entered an era in which severe influenza A infection in patients unable to receive zanamivir must be treated with two drugs - oseltamivir and amantadine - to ensure the use of at least one active antiviral agent. Indeed, the Centers for Disease Control recently issued interim recommendations stating that seasonal influenza $\mathrm{A}$ should be preferentially treated with zanamivir, or, alternatively, with a combination of oseltamivir and an adamantane, particularly in patients who cannot receive zanamivir (31).

\section{CONCLUSIONS}

The present case report illustrates that oseltamivir-resistant seasonal influenza A strains are circulating in North America. Canadian physicians must be aware of current local influenza surveillance data, including resistance patterns, which are available at http://www.phac-aspc.gc.ca/fluwatch/index-eng. php. In addition, contrary to previously held beliefs, oseltamivirresistant viruses are capable of causing severe disease in healthy children, and therefore clinicians should consider empirical combination therapy with oseltamivir and amantadine in severe seasonal influenza A infections.

CONFLICTS OF INTERESTS: All authors state that they have no financial relationships or conflicts of interest relevant to this article to disclose.

CONFIDENTIALITY: Written informed consent for publication of this manuscript has been obtained from the patient's parents.

\section{REFERENCES}

1. Neuzil KM, Mellen BG, Wright PF, Mitchel EF Jr, Griffin MR. The effect of influenza on hospitalizations, outpatient visits, and courses of antibiotics in children. N Engl J Med 2000;342:225-31.

2. Schanzer DL, Langley JM, Tam TW. Hospitalization attributable to influenza and other viral respiratory illnesses in Canadian children. Pediatr Infect Dis J 2006;25:795-800.

3. Moore DL, Vaudry W, Scheifele DW, et al. Surveillance for influenza admissions among children hospitalized in Canadian immunization monitoring program active centers, 2003-2004. Pediatrics 2006;118:e610-e619.

4. National Advisory Committee on Immunization. Statement on influenza vaccination for the 2008-2009 season. An Advisory Committee Statement (ACS). Can Commun Dis Rep 2008;34(ACS-3):1-46.

5. American Academy of Pediatrics Committee on Infectious Diseases. Antiviral therapy and prophylaxis for influenza in children. Pediatrics 2007;119:852-60.

6. Allen UD, Aoki FY, Stiver HG. The use of antiviral drugs for influenza: recommended guidelines for practitioners. Can J Infect Dis Med Microbiol 2006;17:273-84. 
7. Semret M, Fenn S, Newby D, Papenburg J, McDonald J, Loo VG. A multiplex RT-PCR assay for the rapid diagnosis of 10 respiratory viruses. 48th Interscience Conference on Antimicrobial Agents and Chemotherapy, Washington, DC, October 25 to 28. 2008. American Society for Microbiology. (Abst)

8. McGeer A, Green KA, Plevneshi A, et al. Antiviral therapy and outcomes of influenza requiring hospitalization in Ontario, Canada. Clin Infect Dis 2007;45:1568-75.

9. Lee N, Chan PK, Choi KW, et al. Factors associated with early hospital discharge of adult influenza patients. Antivir Ther 2007;12:501-8.

10. McGeer A, Drews S, Davis I, et al. Surveillance for influenza in intensive care units in Toronto, Canada 2006-2007. 47th Interscience Conference on Antimicrobial Agents and Chemotherapy, Chicago, IL, September 17 to 20, 2007. American Society for Microbiology. (Abst)

11. Weinstock DM, Zuccotti G. Adamantane resistance in influenza A. JAMA 2006;295:934-6.

12. Moscona A. Medical management of influenza infection. Annu Rev Med 2008;59:397-413.

13. Bright RA, Medina MJ, Xu X, et al. Incidence of adamantane resistance among influenza $\mathrm{A}(\mathrm{H} 3 \mathrm{~N} 2)$ viruses isolated worldwide from 1994 to 2005: a cause for concern. Lancet 2005;366:1175-81.

14. Reyes F, Aziz S, Winchester B, Li Y, et al. Influenza in Canada: 2007-2008 season update. Can Commun Dis Rep 2008;34:1-9.

15. Centers for Disease Control and Prevention. Influenza activity-United States and worldwide, 2007-08 season. MMWR Morb Mortal Wkly Rep 2008;57:692-7.

16. Matheson NJ, Harnden AR, Perera R, Sheikh A, SymmondsAbrahams M. Neuraminidase inhibitors for preventing and treating influenza in children. Cochrane Database Syst Rev 2007;(1):CD002744.

17. Arabi Y, Gomersall CD, Ahmed QA, Boynton BR, Memish ZA. The critically ill avian influenza A (H5N1) patient. Crit Care Med 2007;35:1397-403.

18. Moscona A. Oseltamivir resistance - disabling our influenza defenses. N Engl J Med 2005;353:2633-6.

19. Hurt AC, Barr IG. Influenza viruses with reduced sensitivity to the neuraminidase inhibitor drugs in untreated young children. Commun Dis Intell 2008;32:57-62.
20. Kiso M, Mitamura K, Sakai-Tagawa Y, et al. Resistant influenza A viruses in children treated with oseltamivir: Descriptive study. Lancet 2004:364:759-65.

21. Sheu TG, Deyde VM, Okomo-Adhiambo M, et al. Surveillance for neuraminidase inhibitor resistance among human influenza $A$ and $B$ viruses circulating worldwide from 2004 to 2008. Antimicrob Agents Chemother 2008;52:3284-92.

22. Reyes F, Aziz S, Macey JF, et al. Influenza in Canada: 2006-2007 season update. Can Commun Dis Rep 2007;33:85-92.

23. Public Health Agency of Canada. FluWatch. 2009. </www.phacaspc.gc.ca/fluwatch/index-eng.php $>$ (Version current at July 3 , 2009).

24. World Health Organisation. Influenza A(H1N1) virus resistance to oseltamivir. 21 March, 2009. <www.who.int/csr/disease/influenza/ h1n1_table/en/index.html> (Version current at July 3, 2009).

25. Herlocher ML, Truscon R, Elias S, et al. Influenza viruses resistant to the antiviral drug oseltamivir: Transmission studies in ferrets. J Infect Dis 2004;190:1627-30.

26. Ives JA, Carr JA, Mendel DB, et al. The H274Y mutation in the influenza $\mathrm{A} / \mathrm{H} 1 \mathrm{~N} 1$ neuraminidase active site following oseltamivir phosphate treatment leave virus severely compromised both in vitro and in vivo. Antiviral Res 2002;55:307-17.

27. van der Vries E, van den Berg B, Schutten M. Fatal oseltamivirresistant influenza virus infection. N Engl J Med 2008;359:1074-6.

28. Govorkova EA, Fang HB, Tan M, Webster RG. Neuraminidase inhibitor-rimantadine combinations exert additive and synergistic anti-influenza virus effects in MDCK cells. Antimicrob Agents Chemother 2004;48:4855-63.

29. Ilyushina NA, Hoffmann E, Salomon R, Webster RG, Govorkova EA. Amantadine-oseltamivir combination therapy for H5N1 influenza virus infection in mice. Antivir Ther 2007;12:363-70.

30. Ison MG, Gnann JW Jr, Nagy-Agren S, et al. Safety and efficacy of nebulized zanamivir in hospitalized patients with serious influenza. Antivir Ther 2003;8:183-90.

31. Centers for Disease Control. CDC health advisory: CDC issues interim recommendations for the use of influenza antiviral medications in the setting of oseltamivir resistance among circulating influenza A (H1N1) viruses, 2008-09 influenza season. December 19, 2008. <www2a.cdc.gov/HAN/ArchiveSys/ ViewMsgV.asp?AlertNum=00279> (Version current at July 3, 2009). 


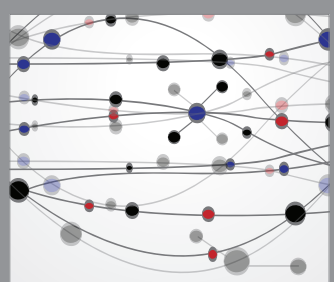

The Scientific World Journal
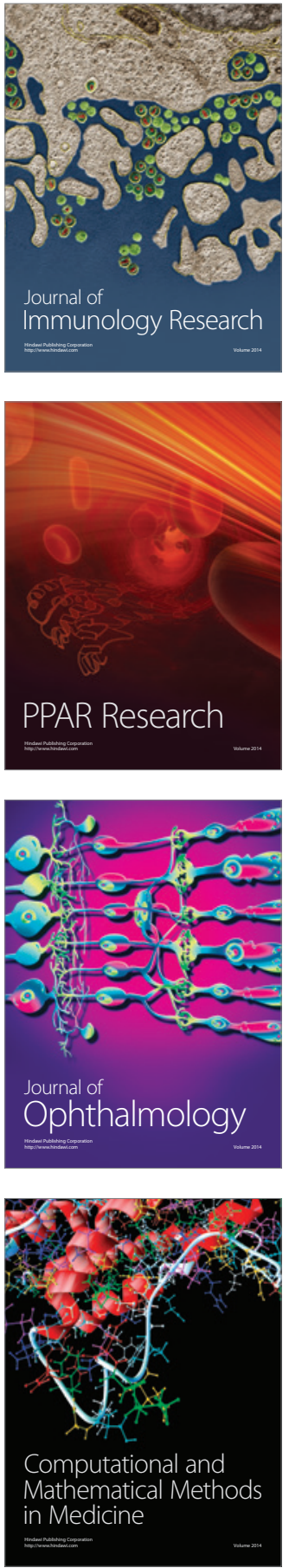

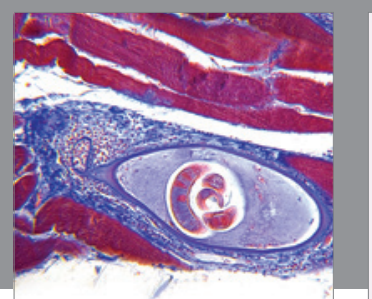

Gastroenterology Research and Practice

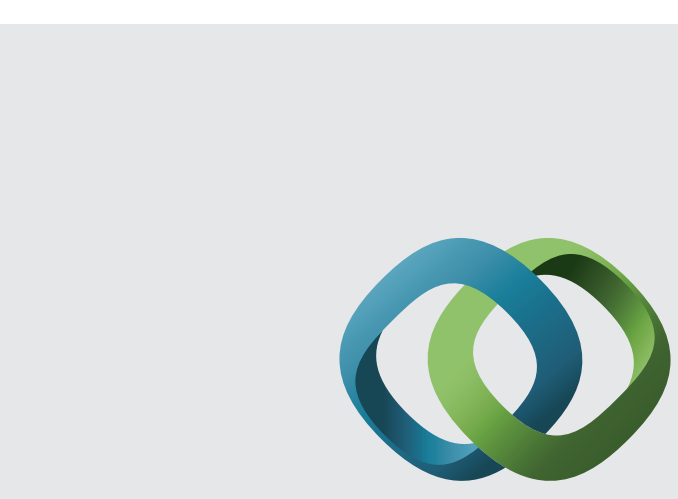

\section{Hindawi}

Submit your manuscripts at

http://www.hindawi.com
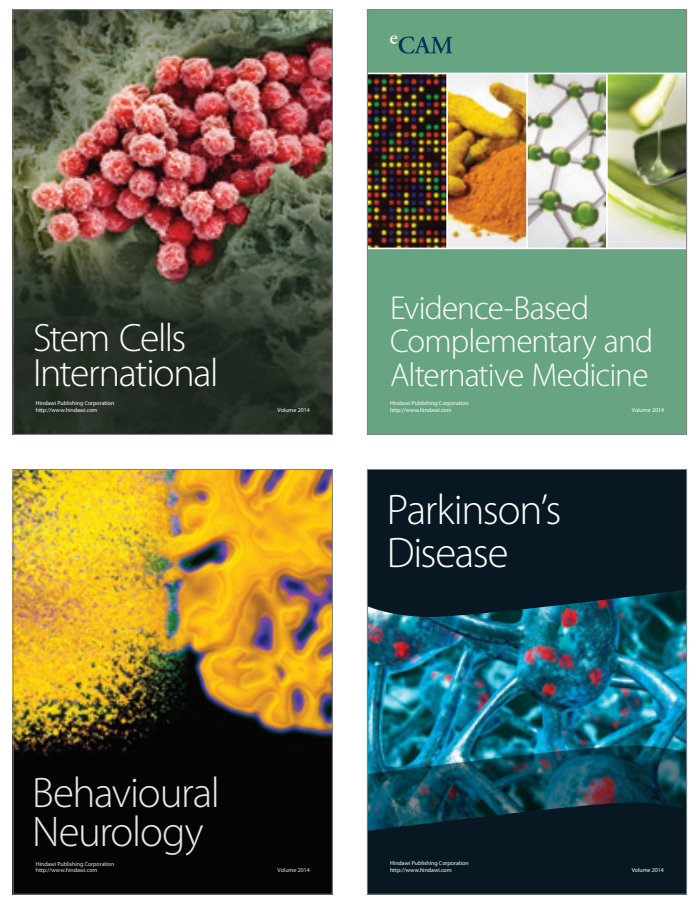
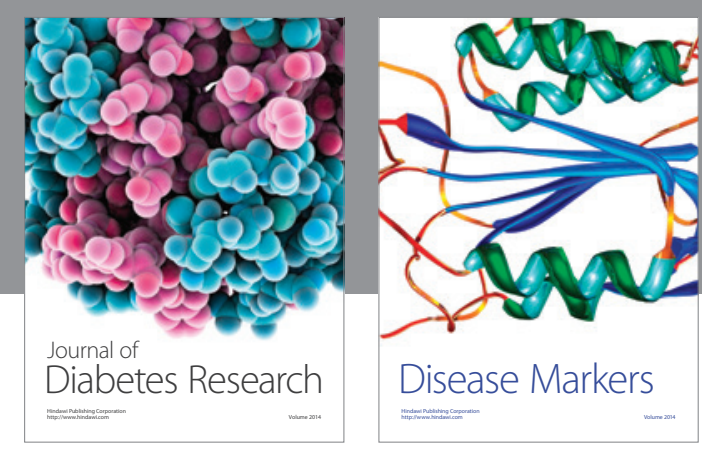

Disease Markers
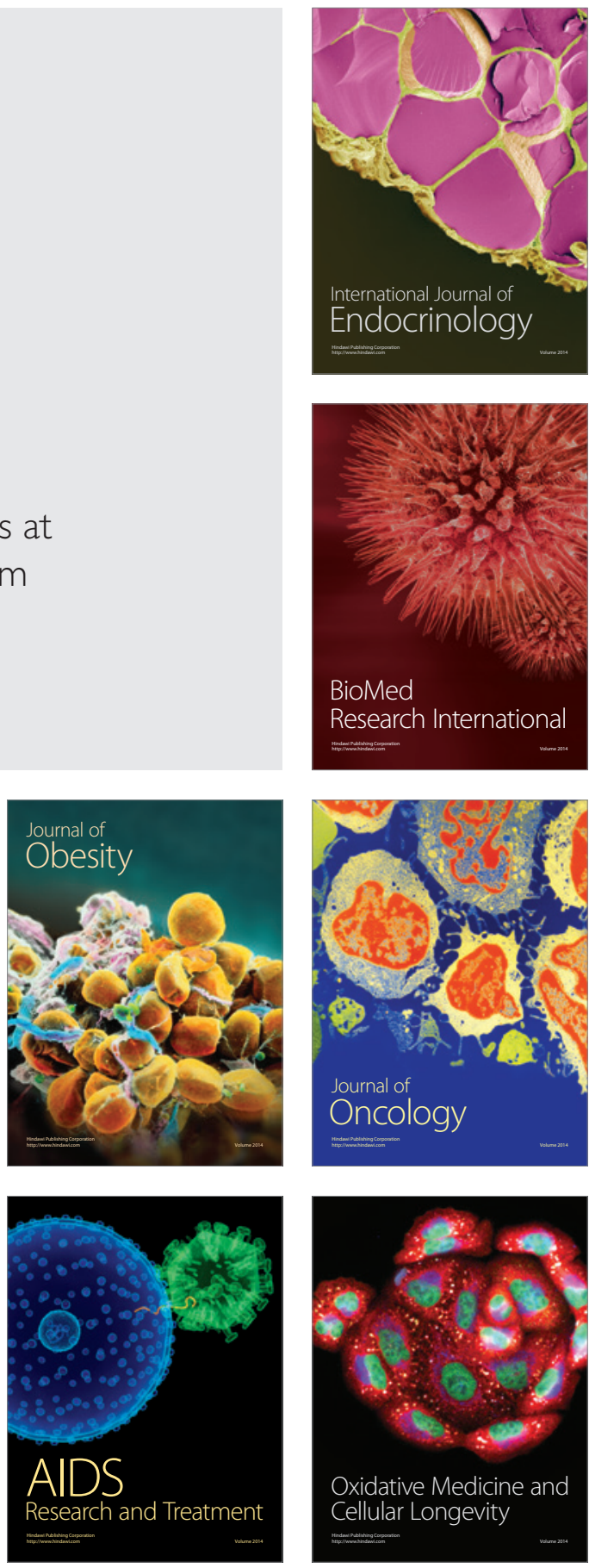